\title{
25-HYDROXYVITAMIN D STATUS IN ELDERLY PATIENTS WITH HASHIMATO THYROIDITIS
}

Fulden Sarac ${ }^{1}$, Sumru Savas ${ }^{1}$, Sefa Sarac $^{2}$, Fehmi Akcicek $^{1}$

1 Department of Internal Medicine, Geriatrics Section, Ege University Medical Faculty/ Izmir/ TURKEY 2Department of Cardiology, Katip Celebi University, Atatürk Training and Research Hospital/ Izmir/ TURKEY

\section{OBJECTIVES}

Low serum levels of 25- hydroxyvitamin D (25(OH)D3) has been reported to be prevalent in several autoimmune diseases.

The aims of the study were 1 . to evaluate the 25 hydroxyvitamin D levels in patients with hashimato thyroiditis (HT), and 2. to investigate the relationships between 25-hydroxyvitamin $\mathrm{D}, \mathrm{TSH}$, free T4, free T3 and anti-thyroid peroxidase (anti-TPO) levels in elderly patients with HT.

\section{METHODS}

Study population included 80 (mean age $58.1 \pm 9.3 \mathrm{yrs}$ ) (60 female, 20 male) patients with HT.

Data such as 25(OH)D3, TSH, fT4, fT3 and anti-TPO tests were retrospectively searched.

Vitamin D insufficiency was defined as (25(OH)D3)

concentrations lower than $30 \mathrm{ng} / \mathrm{ml}$.

\section{RESULTS}

In elderly with HT, mean levels of 25-hydroxyvitamin D were found to be $39.7 \pm 6.5 \mathrm{ng} / \mathrm{ml}$.

However, mean levels of 25-hydroxyvitamin D were $52.0 \pm 12.3 \mathrm{ng} / \mathrm{ml}$ in patients with HT $(<$ age $60 \mathrm{yrs})(\mathrm{p}=0.05)$.

In patients with HT (<age $60 \mathrm{yrs})$ means level of $25(\mathrm{OH}) \mathrm{D} 3$ concentrations were inversely correlated with the antithyroide peroxidase levels $(r=-0,700, p=0.04)$.

And also, in elderly group, mean levels of $25(\mathrm{OH}) \mathrm{D} 3$ concentrations were positively correlated with the fT4 levels $(\mathrm{r}=\mathrm{-}$ $0,700, p=0.04)$.

\section{CONCLUSIONS}

25-hydroxyvitamin D deficiency was significantly higher in elderly.

And also, mean levels of 25(OH)D3 were positively correlated with fT4 in elderly with HT, but inversely correlated with anti-TPO levels in patients with HT (<age $60 \mathrm{yrs}$ ). 